\title{
Impacto de los medios de comunicación en la salud pública
}

Impact of mass media in public health

Carlos Feo Acevedo', Oscar Feo Istúriz²

'Doctorando en Comunicación Universidad de La Habana - Habana, Cuba. Psicólogo social de la Universidad Central de Venezuela - Caracas, Venezuela.

carlosfeoacevedo@yahoo.com

2 Especialista en Salud Pública y Salud de los Trabajadores. Profesor Titular de la Universidad de Carabobo - Carabobo, Venezuela. Consultor del Instituto

Suramericano de Gobierno en Salud de UNASUR.

oscarfeo@msn.com
RESUMO Los medios de comunicación tienen impacto en la Salud colectiva e individual, y son fundamentales para conformar creencias y conductas. Ese impacto está ligado a los intereses de grandes corporaciones, quienes ven en los medios herramientas para alcanzar sus objetivos y estimular la demanda de productos innecesarios y muchas veces perjudiciales para la salud. Se aborda la influencia que ejercen esos medios en la salud pública, particularmente en la promoción de valores y conductas de riesgo. Concluye con propuestas sobre qué hacer, comentando la posibilidad de control social de los medios, y de nuevos modelos de comunicar en salud que permitan promover valores saludables.

PALAVRAS CHAVE: Medios de comunicación; salud pública; comunicación y salud.

\begin{abstract}
Mass media have a fundamental impact on collective and individual health because they profoundly shape human beliefs and behaviors. The impact of mass media is closely linked to the interests of corporations that view the manipulation of beliefs and behaviors as an essential tool to stimulate demand for unhealthy or unnecessary products and services. This article addresses the influence of the media on public health, particularly in promoting unhealthy values and risky behaviors. It concludes with proposals regarding the possibility of social control of the media, and new models of health communication that can promote healthy values and behaviors.
\end{abstract}

KEYWORDS: Mass Media; Public Health; communication and health. 


\section{El rol de los medios de comunicación}

Desde el punto de vista conceptual, los medios de comunicación masivos (MCM) son parte de la superestructura político-ideológica de la sociedad, y mecanismo fundamental para la construcción de la hegemonía necesaria para la reproducción que requiere un Estado para mantener la dominación de una clase o sector social sobre otro. Como señala Ramonet

se domina mucho mejor si el dominado permanece inconsciente. La relación de dominación no se basa únicamente en la supremacía de la fuerza: pasado el tiempo de la conquista llega la hora del control de los espiritus. (RAMONET, 1998 apud AGUDED, 2002).

Es así que, como regla general, los MCM responden a los intereses políticos y económicos de las grandes corporaciones y centros de poder mundial. Además de la función propagandística y de difusión que juegan estos medios a través de los espacios publicitarios, de los programas de información y opinión, así como de los llamados también de entretenimiento (series, telenovelas, dibujos animados, películas, programas de concurso, etc.), proponen/imponen una agenda que construye un patrón de conductas, valores y creencias, de lo que ellos quieren que sea la sociedad y la conducta del común de la gente. Queda así su función 'educativa', que pudiera ser muy importante, soslayada a una función dirigida a subordinar el pensamiento. Se convierten los MCM en armas de dominación masiva. Para comprender por qué esto es así, es necesario conocer la conformación de estos medios: quiénes son sus dueños, y qué otro tipo de actividad económica y política realizan.

\section{Propiedad y concentración de los medios}

Actualmente existen millares de medios masivos de comunicación, la revolución tecnológica e informática permite que cada hora se suban al internet miles de horas de vídeos, cada minuto se crea un nuevo blog, pareciera que el acceso y posibilidad de producir información se multiplica y democratiza, sin embargo, la gran concentración de la propiedad de los medios es alarmante y hace que la uniformidad del contenido sea abrumadora. Efectivamente, miles de estos medios están en manos de pocas personas y cada vez más su concentración es mayor. Nos resulta acertada la frase de Galeano, quien afirma:

nunca tantos han sido tan incomunicados por tan pocos. Cada vez son más los que tienen el derecho de escuchar y de mirar, pero cada vez son menos los que tienen el privilegio de informar, opinar y crear. (GALEANO, 2009).

Un análisis sobre la propiedad de los medios realizado por Chomsky y Herman (1990) y confirmado más recientemente por Carmona (2007), determina que en Estados Unidos, 29 organizaciones son las responsables de la producción de más de la mitad de los más de 25 mil medios de comunicación existentes en el país, y son ellas quienes definen la agenda de contenido y generan las noticias nacionales e internacionales. Las cuatro principales agencias de noticias (AP, UPI, Reuters y AFP) generan el $80 \%$ de las noticias que circulan en todo el mundo. Pero resulta que los propietarios de estos grandes medios están directamente vinculados con otros rubros de la economía, como la banca, la producción de armamento, la agroindustria, las compañías petroleras, las compañías automotrices, o la industria farmacéutica. Un ejemplo: General Electric y Westinghouse, empresas inicialmente de manufactura de productos para el hogar, ahora también fabrican armamentos, son parte del complejo industrial de la salud y propietarias de grandes medios de comunicación.

Los propietarios de los MCM incursionan en la actividad política, y cuentan con representantes en el gobierno; este entramado de alianzas entre MCM, banca, complejo médico y militar industrial, empresas petroleras y gobiernos, es una fórmula que existe en la mayor parte del mundo, y es muy fuerte enspañ los EEUU, donde se genera la mayoría de los contenidos mediáticos que se ven en el mundo. En Estados Unidos, en los años 80 la mayoría de los directores de 
los principales diez medios de comunicación también pertenecían al mundo empresarial o de a la banca. Sólo el sector financiero poseía el $44 \%$ de las acciones de los periódicos y el $35 \%$ de la radio. Además, estas grandes corporaciones financian y dirigen organizaciones intelectuales de derecha (los llamados think tanks). Por ejemplo, General Electric creó el American Enterprise Institute para promover el pensamiento neoliberal en el mundo. Y, así como poseen canales de televisión, radios, navegadores de internet, medios virtuales, periódicos, editoriales, agencias de noticias, productoras y distribuidoras cinematográficas, grupos de presión e institutos académicos que permiten crear y solidificar determinadas matrices de opinión, también operan directamente con el gobierno. Esta relación es simbiótica: medios-corporaciones-gobierno. Otro ejemplo: 20 $\%$ de los directores de los principales MCM en Estados Unidos en los 80 eran antiguos altos funcionarios del gobierno. Esta tendencia, lejos de atenuarse, se ha ido incrementando con el tiempo. El hecho de que los cuatro principales funcionarios de la administración de George W. Bush fuesen también directivos de grandes empresas petroleras y de armamentos no pareció escandalizar a nadie, y tampoco escandalizó a la opinión pública el hecho de que los principales contratos surgidos de la guerra a Irak beneficiaran precisamente a esas empresas. Incluso empresas que parecen tan inocuas como Walt Disney, que en nuestro imaginario la asociamos a la producción de películas y gestión de parques de atracciones, tienen intereses que van más allá de ello. Walt Disney posee más de 50 canales de radio y televisión (entre los cuales se encuentra la poderosa $A B C$ ), y está involucrada en la explotación de gas y petróleo. Rupert Murdoch, presidente de la News Corporation, podría considerarse como el modelo del magnate político mediático. Controla la cadena de televisión Fox, y es propietario de los diarios, agencias de noticias y estaciones de radio más influyentes en Norteamérica, y, por extensión, en todo el continente. En Chile es dueño del 100 por ciento de la televisión por cable y satélite. Pero su influencia traspasa el continente, poseyendo medios importantes en Australia y Europa. Recientemente estuvo involucrado en un escándalo en Inglaterra, por haber utilizado una red de espionaje para develar los secretos de personajes políticos y de la farándula. También es dueño del indicador Dow Jones, que controla gran parte de la economía especulativa del mundo. Según la revista Forbes, su fortuna asciende a más de 9 mil millones de dólares, ubicándolo dentro de las 100 primeras fortunas del mundo. Esta concentración de los medios tiene también su versión local: el empresario mexicano Ángel González es el propietario de todos los canales de televisión abierta que existen en Guatemala, de dos canales de TV abierta en Chile y de otro en Argentina. También controla el espacio mediático en Costa Rica, con la propiedad de tres medios televisivos (que ocupan más del $65 \%$ de la audiencia nacional), y de doce estaciones de radio. En total posee una treintena de estaciones de televisión y setenta de radio en toda América Latina. El cubano venezolano Gustavo Cisneros opera en 39 países con 70 compañías de radiodifusión, televisión e internet. Todos ellos son un ejemplo de la concentración mediática en Nuestramérica y todos ellos no sólo tienen fuertes vínculos con el poder económico, sino que también son representantes del mismo. Esa tríada Medios-Corporaciones-Gobierno se hace más visible en algunos casos emblemáticos: el actual presidente de Chile, el empresario Sebastián Pińera, era presidente de Chilevisión y de LAN Chile, tiene grandes intereses en el negocio inmobiliario, es dueño de varias constructoras, posee más de $115 \mathrm{mil}$ hectáreas de terreno, y ha sido presidente de dos bancos emblemáticos: el banco Talca y el Citicorp. Todos estos negocios, y otros más, lo convierten en una de las principales fortunas del continente.

El actual presidente de Colombia, Juan Manuel Santos, tiene una hoja de ruta similar. Siendo de una familia de empresarios, periodistas y presidentes, ha sido testigo de primera fila de una larga y armoniosa relación medios-corporaciones-gobierno. Él mismo se ha paseado por todos estos espacios, ha sido director del principal diario del país, El Tiempo, del cual su familia es la principal accionaria, ha dirigido algunas empresas familiares, ha sido ministro, y ahora presidente y claro representante del capitalismo en el continente.

En Brasil, De Moraes (2011) afirma que seis empresas controlan el mercado de televisión en Brasil, y la red Globo detenta cerca de la mitad de este mercado, 
señalando que esas empresas controlan 138 de los 668 medios de transmisión existentes (televisoras, radios y periódicos) y un 92 por ciento de la audiencia televisiva.

Esta interacción medios-corporaciones-gobierno en algunas ocasiones se rompe. Con la llegada del nuevo milenio hemos visto la propagación de esta ruptura, protagonizada por países como Venezuela, Bolivia y Ecuador, quienes se han atrevido a enfrentar el poder mediático, y planteado la construcción de una sociedad basada en un nuevo modelo de desarrollo y consumo. Ya lo había hecho Cuba a partir de 1959. Cuando esto sucede, el enfrentamiento entre los medios y el gobierno es evidente, y los medios asumen el papel de principales opositores políticos a esos procesos. Cuando esta tríada se rompe, se activan mecanismos de presión que buscan restablecerla. En Nuestramérica uno de estos mecanismos es la SIP, Sociedad Interamericana de Prensa, que reúne a los grandes dueños de medios del continente. Este organismo ha sido creado y es financiado y monitoreado por el gobierno de los Estados Unidos. Dentro de sus estatutos está la defensa de la libertad de prensa, pero su objetivo central es el mantenimiento del status quo y el ataque a los gobiernos que han marcado una ruptura en esa tríada medios-corporaciones-gobiernos. Curiosamente los países mejor vistos por la SIP (Honduras, Colombia, Estados Unidos, Panamá) son quienes más atentan contra la libertad de expresión, e incluso la libertad de prensa. Las violaciones de derechos humanos en estos países representan las más altas de todo el continente, pero los medios hegemónicos, en un malabaresco ejercicio de proyección, acusan a los gobiernos de izquierda del mal que ellos mismos padecen. En el financiamiento de la SIP participa la National Endowment for Democracy, una organización del Departamento de Estado norteamericano encargada de desestabilizar gobiernos que no sigan sus intereses (CARMONA, 2007). Además, es claro que en países como Venezuela y Bolivia, los medios de comunicación privados se han convertido en el principal factor de oposición a esos gobiernos.

\section{Libertad de expresión vs libertad de prensa}

La tan cacareada libertad de expresión, como lo vimos con el ejemplo de la SIP, suele ser uno de los pretextos favoritos del poder económico y político hegemónico para atacar a los países con gobiernos progresistas. Usan este término para confundir a la opinión pública. Un término por demás que ha sido mediáticamente construido como un derecho fundamental. Y ahí entra la confusión, pues una crítica que pueda hacer un determinado gobierno hacia un medio no es un ataque per se a la libertad de expresión. De hecho, quienes más violan la libertad de expresión son precisamente los medios de comunicación, quienes evaden los derechos a réplica y, con sus políticas editoriales y las presiones de las empresas relacionadas con el medio, impiden la publicación o transmisión de un tema determinado o de una opinión determinada, que no sólo puede ser de un ciudadano cualquiera, sino también de los mismos periodistas. De la manera más sutil se ejerce una constante y firme censura. La trama primera a la que nos vemos sujetos es confundir libertad de expresión con libertad de prensa. Para comprender esta confusión es preciso definir ambos términos. La libertad de expresión tiene que ver con la posibilidad que tenemos los ciudadanos de decir lo que pensamos; mientras que la libertad de prensa tendría más que ver con la libertad que puedan tener los medios para decir lo que quieran, incluidas mentiras y manipulación en función de sus intereses. Esto nos lleva a otra diferenciación: el alcance que pueda tener cualquier individuo sobre un tema es generalmente menor que el alcance que pueda tener la opinión de un periodista en un medio de comunicación masivo, o más aun, la opinión del medio expresada por un periodista. Recordemos que en la mayor parte de los casos, los periodistas deben ceñirse a la línea editorial del medio y, por lo tanto, no expresan opiniones personales sino, las más de las veces, corporativas. En este sentido, la responsabilidad de este periodista (o del medio) es mucho mayor,

[...] es una responsabilidad que tiene directa relación con las consecuencias o las implicaciones que esos contenidos puestos en circulación por el periodista o el medio van a tener en cada uno de nosotros (...) La responsabilidad de la información, que es social e involucra a la colectividad, debe garantizar que no se pueda 
decir cualquier cosa, mentir, manipular o decir algo que vaya en contra del bien común por defender intereses particulares. Así, la libertad de información o de prensa se parece más (cada vez más) a un deber antes que a un derecho, aquel que obliga éticamente a los periodistas a asumir la responsabilidad, en primera persona y en nombre del medio, que implica la puesta en circulación de contenidos públicos relevantes, y que son tales porque afectan a la vida de todos. (CERBINO, 2009).

Sin embargo, esta libertad de prensa ilimitada pretende estar por encima de las regulaciones y controles que todo Estado debe hacer sobre las instituciones que funcionan en el país. Los medios construyen una ideología que pareciera les permite estar exentos de cualquier responsabilidad social. Pero al profundizar nos damos cuenta de una segunda trama: los mismos medios se han encargado de fusionar esta libertad de prensa con la 'libertad de empresa', donde los intereses de los dueños de los medios se convierten en un derecho fundamental que no puede ser atacado, ni objetado. Además, dentro de esta libertad de prensa se fue construyendo el concepto de objetividad, como una manera de aumentar la credibilidad de lo que la prensa expresa. De este modo, los medios de comunicación pasan a estar más allá del bien y del mal, y los mensajes que a través de ellos se muestran son recibidos, aceptados y asimilados con facilidad. Los medios se convierten en los garantes del status quo, a través de la fabricación de consenso.

\section{Fabricación de consenso}

La función de dominación que ejercen los medios se presenta en forma muy sutil, tanto que muchas veces pasa desapercibida. En este sentido, y asumiendo el concepto gramsciano, la dominación implica no sólo 'represión' sino, sobre todo, construcción de hegemonía. El mensaje presentado por los medios no es impuesto por violencia o por obligación, sino más bien aceptado como un contrato. En este sentido, la función fundamental de los medios es la fabricación de consenso, hacer que la gente piense y consuma como ellos quieren, el consenso que expresa los intereses de las élites económicas y financieras. Y en un mundo consensuado y hegemónico, los conflictos (de clase, de género, de raza) desaparecen. Chomsky e Herman señala que

los medios son instituciones ideológicas efectivas y poderosas, que llevan a cabo una función propagandistica de apoyo al sistema mediante su dependencia de las fuerzas del mercado, los supuestos interiorizados y la autocensura. (CHOMSKY; HERMAN, 1990, p. 353).

Lippmann (1992), clásico de las teorías de la comunicación, afirma que la fabricación de consenso, como rol de los medios, también implica una función de propaganda. Sin duda, la actividad propagandística es uno de los aspectos más relevantes del contenido de los medios de comunicación de masas. De esta manera, los grandes MCM responden a intereses bien definidos, y el discurso que ofrecen emite propaganda política, crea opinión pública y persuade a favor de la ideología dominante. Ante tal avalancha de mensajes, que llegan incluso de manera subconsciente, el sujeto va desapareciendo, para convertirse en potencial consumidor y en reproductor del status quo. Es la alienación por los medios.

\section{La TV y la construcción de la realidad}

La televisión es uno de los elementos claves en la fabricación de consenso. Adorno (1969), entendía a la televisión como el principal canal propagador de la cultura dominante, y le otorgaba un poder especial: la vertiginosa dinámica societal sumada a la súper exposición y al cuidadoso ensamblaje de los mensajes, no permite espacios para alguna reflexión sobre los mismos, ni sobre el impacto que ellos producen, por lo tanto, el mundo reflejado en la pantalla terminaría remplazando al real. El hecho de la imagen le da una connotación más real a lo que se percibe, y cuando se trata de un hecho informativo (y no de ficción), lo que se ve es real, es lo que está realmente sucediendo. Pero no sólo eso, a nivel cognitivo lo que se ve es LO real. En esta era de 
las telecomunicaciones lo visual ha cobrado una nueva dimensión. Sartori afirma que

\section{[...] el video está transformando al homo sa-} piens, producto de la cultura escrita, en un homo-videns, para el cual la palabra está destronada por la imagen. La imagen, por su propia naturaleza, se dirige más hacia la afectividad de las personas que a la razón. Existe además una fascinación por las imágenes tomadas en directo: la mera muestra de una imagen es suf-ciente para darle todo su significado. Se tiende a desplazar la realidad por su puesta en escena: es la historia telefalsificada. (SARTORI, 1998, p.11)

Pero la imagen no viene aislada, viene con un relato, y este relato termina de darle sentido al mensaje (a la noticia). Sin embargo, la narración del mensaje es secundaria, está en función de la imagen, comenta la imagen. Ya el significado viene dado por el relato de la imagen (a través de un periodista), por lo que existe un empobrecimiento de la capacidad de entender. Ya todo está dicho. Para el tele-espectador ya no hay que realizar un proceso cognitivo de abstracción e interpretación de lo que se está viendo. En este sentido, lo que se ve es LO real, pero también es lo que dice el medio que es. De esta manera, la televisión no representa una realidad, sino que, sobre todo, la construye. Y esta 'realidad' está a merced de los dueños de comunicación que cada día tienen mejores y más sofisticadas herramientas tecnológicas para manipular esta realidad. Un ejemplo emblemático y que se convirtió en caso de estudio de las manipulaciones mediáticas, fue el golpe de estado realizado en Venezuela en abril del 2002 y el breve derrocamiento del presidente Chávez. Autores como Villegas (2009) y Britto García (2008) han analizado estos sucesos, revelando que, si bien los medios siempre han tenido una función política en la sociedad, nunca habían llegado al extremo de transformarla del modo que lo hicieron en Venezuela. A través sobre todo de la televisión y la prensa, los opositores lograron crear una matriz de opinión completamente desfavorable al gobierno, luego convocaron abiertamente a un paro que fue presentado como general y nacional, para luego convocar una marcha que estaba pensada como la fase final del golpe. Una imagen televisiva fue clave como justificación del golpe: una cámara de Venevisión, principal canal privado del país, mostraba de manera fija, la imagen de un grupo de partidarios de Chávez que disparaban. El relato del periodista completaba la imagen al describir que 'estaban disparando a la marcha pacífica de la oposición'. Este supuesto hecho sangriento permitió justificar el alzamiento militar. Así, con cámaras de por medio, un grupo de militares desconoció el gobierno, mientras que la realidad era que unos francotiradores contratados por los cerebros ocultos del golpe, masacraban a la población creando las víctimas necesarias para justificar el intento golpista. El día siguiente, con Chávez prisionero, las mismas pantallas develaron parte de la conspiración y orgullosas se mostraban a ellas mismas como principales responsables. Los héroes eran los dueños de los medios y los periodistas los que construían la noticia, los que construían 'la realidad'. Lo que nunca esperaron fue la inmensa rebelión popular que, horas después, rescató al presidente Chávez, y se conocieron las verdaderas imágenes que habían sido manipuladas. Para mayor información se han producido varios documentales sobre el tema, uno de ellos de Ángel Palacios, 'Puente Llaguno: claves de una masacre' puede ser conseguido fácilmente en la red.

Conclusión: la TV (y sus dueños) construyen la realidad. Pero esa realidad no es infalible ni omnipotente. Cerramos este apartado con esta apropiada cita del periodista Regis Debray "lo que nos hace ver el mundo es también lo que nos impide verlo" (DEBRAY, 1994, p.300).

\section{Medios de comunicación y salud}

En el sector salud los medios de comunicación masivos juegan un rol de gran importancia, y la tríada corporaciones-medios-gobiernos sigue vigente. El contenido mediático crea y consolida conductas, creencias y valores, muchos de los cuales van dirigidos a crear seres individualistas, violentos, competitivos y sobreconsumidores. Este ser 'tele-fabricado' y en proceso de alienación, 
asume los mensajes mediáticos que van a incidir, en menor o mayor grado, en adoptar determinadas actitudes y comportamientos, colectivos e individuales, muchos de los cuales pueden ser nocivos para su salud.

\section{Promoción de valores y conductas de riesgo en salud}

La relación medios-corporaciones-gobiernos es simbiótica, los mensajes mediáticos están imbricados con los intereses y poderes económicos y políticos. En este sentido, las grandes corporaciones han encontrado en los medios su mejor aliado para vender sus productos, la mayor parte NO necesarios para la vida. Sin embargo, el aparataje de la publicidad trata de convencernos de que son productos necesarios para vivir mejor. Según el informe de publicidad de MagnaGlobal (2012), se destinaron 411 mil millones de dólares a gastos de publicidad en todo el mundo. La industria publicitaria no ha sido afectada por la crisis económica mundial. Al contrario, tuvo un crecimiento de $5,4 \%$ con relación al año anterior. La mayor parte de esta inversión fue destinada al medio televisivo (41,12\%), y más de la tercera parte de este gasto fue generado en un solo país, los Estados Unidos.

Es visible la dimensión del bombardeo publicitario al que se nos expone a través de los medios de comunicación. Pero más allá de la herramienta publicitaria, se emplean otros mecanismos que vulneran nuestra vida y salud. Uno de los ejemplos más ilustrativos es la promoción del consumo de cigarrillos y los esfuerzos de la industria tabacalera para vender su producto en detrimento de la salud. En los años 90, a raíz del juicio a la industria tabacalera, la Organización Panamericana de la Salud (OPS) (ORGANIZACIÓN PANAMERICANA DE LA SALUD, 2002) realizó una investigación centrada en los dos líderes de esta industria: British American Tobbaco y Philip Morris. Su estudio se centró en el análisis de más de diez mil documentos filtrados al público, donde se mostraba que a pesar de los numerosos estudios que vinculaban el consumo del cigarrillo al cáncer de pulmón, las empresas tabacaleras iniciaron una intensa campaña para desmontar esta evidencia científica, lo que implicó la "compra" de investigadores que desacreditaran los estudios científicos que vinculaban el humo de tabaco con el cáncer. Esta campaña contó con los tradicionales medios de comunicación, y las empresas tabacaleras aumentaron sus gastos de publicidad y contrataron periodistas de estos mismos medios. Sembrar la duda es su objetivo, sin embargo, la evidencia es abrumadora: según diversos informes de la Organización Mundial de la Salud en el 2008 murieron 1,4 millones de personas por cáncer de pulmón y por lo menos el 80\% eran fumadores. En América Latina la industria tabacalera actuó de manera similar y financió proyectos para desviar la atención del cigarro y centrarla en otros factores contaminantes del aire, señalando que podían ser más nocivos que el cigarrillo. Esta lucha contra la industria tabacalera ha sido una de las más visibles y mediatizadas de los últimos tiempos, y si bien es cierto que se ha logrado algunos triunfos en cuanto a la regulación de la actividad publicitaria del tabaco y de su venta, las ganancias no han mermado, al contrario, la empresa Philip Morris, principal compañía tabaquera del mundo, que abarca el 15\% del mercado mundial, ha visto aumentar sus ganancias. Según un comunicado de prensa de Philip Morris (2011), sus acciones han crecido $22,55 \%$ en tan sólo un ańo, y los ingresos netos han aumentado $26,4 \%$ en relación al año pasado, ubicándose en 20.706 millones de dólares para los primeros tres trimestres del año 2011. Aunque es importante hacer notar que la presión social y las acciones legales han ganado aliados dentro de algunos medios, la presión sutil que ejercen los grandes poderes económicos de la industria tabacalera siguen existiendo. No es gratuito que para el año 2011 Philip Morris haya aumentado en un $25 \%$ sus gastos de publicidad.

Así como sucede con la industria tabacalera, también sucede con las bebidas alcohólicas, la industria cosmética, la industria pornográfica, fortalecida gracias a la incesante instrumentalización de la mujer, o la industria alimenticia, sobre todo aquella que produce 'alimentos o bebidas chatarra', las cuales promueven campańas que atentan contra la salud de las personas y, tal como la industria tabacalera, no sólo se encargan de publicitar sus nocivos productos, sino también de hacer lobbys para favorecer un marco legal que permita la perpetuación 
de esta hegemonía. Las grandes transnacionales de la agroalimentación, asociadas en la International Food and Beverage Alliance (IFBA) participan activamente en las negociaciones para la regulación de la alimentación en el mundo e incluso intentan incidir en las políticas agrarias que les permitan y garanticen la tenencia de la tierra. Curiosamente, uno de los representantes más activos de la IFBA es Derek Yach, director de política sanitaria global de PepsiCo, quien fuera hasta el 2007 director ejecutivo de enfermedades no contagiosas de la OMS (SHAH, 2011).

Mención especial requiere la televisión dirigida a los niños, que va acompañada de un alto contenido propagandístico de juguetes, ropa infantil y comida chatarra, tratando de convertir a nuestra población infantil en consumidores precoces, lo cual unido a la promoción de valores y conductas poco saludables y en muchos casos violentas, configura un atentado contra el futuro de nuestros niños y nińas. Los MCM, al ser actores esenciales en esta dinámica publicitaria, contribuyen al deterioro de la salud de la población, tratando de convertir a las personas en espectadores pasivos y consumistas.

\section{La industria farmacéutica, los medios y la salud}

En relación a la industria farmacéutica, su relación con los medios no se limita a la promoción de productos farmacéuticos, sino que actúan para crear matrices de opinión que favorecen la introducción de un determinado medicamento o la promoción de una determinada enfermedad. Uno de los casos más recientes fue la gripe AH1N1. En marzo del 2009, los medios se hicieron eco de una nueva pandemia que amenazaba con acabar con buena parte de la humanidad. La OMS pronosticaba que entre un 25 a $30 \%$ de la población mundial podía verse afectada. De igual manera el CDC de Estados Unidos presentaba un informe donde pronosticaba que entre 60 y 120 millones de personas en Estados Unidos podrían verse afectadas, y que entre 30 y 90 mil podrían morir; la gripe normal provoca en Estados Unidos entre 30 y 40 mil muertes al ańo, pero no es considerada pandemia, ni tiene tanta cobertura mediática (FLORES, 2009). Durante semanas los MCM, unos más apocalípticos que otros, ayudaron a crear un ambiente de zozobra y de indefensión en la población, que obligó a los gobiernos y ministerios de salud a realizar 'compras nerviosas'. Primero comenzaron a venderse los tapabocas, luego el Tamiflu de Giliad, (cuyo director ejecutivo había sido Donald Rumsfield, Secretario de Defensa de EEUU en el gobierno de G.W. Bush), y que fue vendido a Roche para su producción masiva, para luego dar paso a las vacunas. Caso paradigmático sería Francia que compró 90 millones de vacunas (calculando dos dosis para cada uno de sus habitantes) y luego solamente utilizó 5 millones (RAMONET, 2009).

Pero más allá del redimensionamiento mediático de enfermedades y problemas de salud que logra impulsar la industria farmacéutica en beneficio de sus intereses, también crean nuevas enfermedades y patologías, para vender medicamentos. Los datos son claros y abrumadores: los grandes laboratorios no sólo investigan y fabrican medicamentos, sino que también crean enfermedades. Y en esta construcción de la enfermedad los medios de comunicación suelen ser las primeras fuentes de información para la población, donde los propósitos, calidad y confiabilidad de la información que brindan con frecuencia suele ser falsa, incompleta, contradictoria o confusa, en cuyo caso resulta perjudicial tomar esas fuentes como referencia confiable.

Otro de los ejes de acción de la industria farmacéutica y los medios tiene que ver con las campañas llevadas a cabo para desprestigiar la producción y distribución de medicamentos genéricos. Como ejemplo, está el caso de la demanda internacional que realizaron 39 empresas farmacéuticas en 1998 contra el gobierno sudafricano, por una ley aprobada por el presidente Mandela para facilitar el acceso a los medicamentos antirretrovirales de los pacientes con VIH a través de la importación de medicinas a menor precio y de genéricos (SINGH, 2001). Finalmente, tres años después, las 39 empresas farmacéuticas retiraron la demanda, gracias a una fuerte contracampaña que el gobierno sudafricano llevó a cabo a nivel internacional. Este lobby de la industria farmacéutica para frenar el ingreso de los medicamentos genéricos es muy fuerte y cuenta con la 
complicidad de las grandes corporaciones mediáticas. Recordemos que el mercado mundial farmacéutico representa unos 950 mil millones de dólares al año y tiene el margen de ganancia más amplio del sector económico, por cada dólar invertido en la fabricación de un medicamento se pueden obtener incluso hasta mil dólares en el mercado (RAMONET, 2009). Para contrarrestar la producción y distribución de genéricos la táctica más frecuente es su desprestigio mediático, y también el fortalecimiento jurídico-legal del derecho de la propiedad intelectual, así como las leyes de patente fortalecidas en los tratados de libre comercio. Comenta Ramonet (2009) que en un estudio realizado por la Comisión Europea se determinó que el lobby farmacéutico para retrasar la concesión de autorizaciones de entrada en el mercado a los genéricos ha ocasionado, en los últimos cinco años, un sobregasto innecesario de cerca de 3.000 millones de euros para los consumidores y un $20 \%$ de aumento de gastos para los Sistemas Públicos de Salud.

\section{El Lobby contra las Reformas del Sistema de Salud}

Una de las estrategias más y mejor utilizadas por los grandes intereses del complejo médico industrial está relacionada con el descrédito y la destrucción de los Sistemas Públicos de Salud. Para ello inundan al país de noticias que revelan la ineficiencia de los servicios de salud hospitalarios, siempre partiendo del concepto de que lo público no funciona, y reforzando la medicalización de la vida cotidiana, que reproduce un sistema de salud centrado en la enfermedad, lo que a su vez repercute en los márgenes de ganancia de la industria farmacéutica.

Pero la industria farmacéutica no es la única interesada en impedir las transformaciones del Sector Salud. El mundo de la banca y de las aseguradoras privadas, desde los tempranos ańos 90, han intensificado su accionar en la salud. La creación de Administradoras de Fondo de Pensiones ha sido muy exitosa y ha construido un modelo para la privatización no sólo de las pensiones sino de toda la Seguridad Social, y en ella tiene un espacio central la atención en salud. El papel que han jugado los medios en la construcción de las condiciones pro privatizadoras ha sido tan intenso, que incluso muchas de las reivindicaciones de la lucha de los trabajadores tienen que ver con conseguir un seguro privado que garantice la salud de su gremio, por fuera de las responsabilidades que debe tener el Estado para hacerlo. Sin embargo, gracias al nuevo espíritu que recorre Nuestramérica, se han fortalecido las voces que, contra viento y marea (o valdría mejor decir, contra medios y corporaciones), han logrado confrontar las políticas privatizadoras e imponer en la agenda político-sanitaria el tema de la Universalidad de la Salud y reivindicar la Salud como un derecho social y humano fundamental, y no una mercancía. En este proceso de ruptura, nuevos medios contrahegemónicos están ocupando cada vez más espacios y acompańando estas nuevas luchas por una vida digna.

\section{Conclusiones ¿qué hacer?}

Ante este complejo panorama en el cual el poder de los medios de comunicación se sobredimensiona y parece omnímodo, las personas no pueden concebirse como sujetos pasivos y víctimas de la alienación mediática por esencia. Los colectivos humanos son actores sociales con capacidad de romper esa cápsula mediática, pero para ello es necesario el conocimiento y reflexión constante sobre la naturaleza de los MCM y su papel en la sociedad. Bolivia recientemente demostró cómo la fortaleza e identidad cultural de ese pueblo fue factor esencial en la lucha contra la alienación y la colonización mediática: la emblemática empresa de comida chatarra McDonalds se rindió ante la tenacidad cultural de este pueblo y optó por cerrar sus puertas e irse del país, pues económicamente no le era rentable. La población boliviana, fortalecida en su identidad cultural, no abandonó su paladar al mejor postor y sigue prefiriendo sus ricas comidas tradicionales. Es por ello que consideramos que el rescate de la historia y la revalorización cultural de nuestros pueblos es un factor determinante para contrarrestar los efectos nocivos de los medios masivos de comunicación, en un mundo regido por el capital. Fortalecer las bases de una cultura 
contrahegemónica permitirá tener más herramientas a la hora de decidir en qué creer, cómo actuar, qué comer, cómo vestirnos, cómo relacionarnos. Es necesario volver al sentido original de la comunicación, que etimológicamente viene del latín communicare que significa 'común', donde comunicación sería entonces 'poner en común, compartir algo'. Tomando en cuenta esta concepción, tendríamos que repensar el sentido de unilateralidad con que se manejan los medios de comunicación, que siguen el modelo clásico: emisor, mensaje, receptor. Y una manera en que el receptor sea partícipe de esta nueva comunicación, es que a él también se le escuche.

\section{El Control social de los medios}

Es imprescindible que la sociedad asuma que tiene un papel que cumplir en el entramado comunicacional de los medios masivos. Y ese papel no es sólo el de ser un ente pasivo ante la televisión o la radio o la computadora, sino también el de organizarse y presionar para crear espacios de interlocución con los medios que le permitan ejercer un control social sobre los mismos. Hay que reconocer que la prensa fue uno de los primeros medios en intentar hacer un acercamiento de mayor reciprocidad con el lector. Para ello creó espacios donde los lectores podían expresarse sobre determinado tema o incluso realizar alguna denuncia. Pero hubo una figura que tuvo aún mayor relevancia en este sentido, y fue la creación del Ombudsman (palabra que viene del sueco y quiere decir literalmente 'representante del pueblo'), que es una persona o grupo, generalmente de la sociedad civil organizada, al que se le ofrece un espacio en el diario donde asume una postura en defensa del lector y podría eventualmente visibilizar alguna manipulación informativa de ese mismo medio donde participa como representante del pueblo. En relación a otros medios existen algunas incipientes experiencias de creación de comités de usuarios, que puedan tener alguna participación en el contenido de la programación del medio. Es evidente que los intereses de los medios pueden ser completamente contrarios a los intereses de los ciudadanos, y en relación a la salud esta contraposición es clara. Por ello es necesario que estos comités adquieran herramientas para que puedan hacerse oír (la creatividad de las manifestaciones, la alianza con personal interno al medio), sobre todo ante medios sin ninguna vena democrática. Pero para que esta acción pueda ser efectiva y constante en el tiempo es necesario también que esté amparada en un marco legal. Afortunadamente, hoy día muchas legislaciones en los países de Nuestramérica han permitido, e incluso promovido, la creación de estos espacios. En países como Venezuela se aprobó la Ley de Responsabilidad Social en Radio y TV (VENEZUELA, 2004), que es una de las más avanzadas en el mundo; en ella se reafirma el dominio público del espacio radioeléctrico, y además de la regulación sobre el contenido publicitario, se promueve la participación ciudadana como eje para el control social de los medios como manera efectiva de regular su rol en la sociedad. De igual manera, el legislativo boliviano aprobó recientemente una nueva ley de medios. Aunque ambas leyes se asemejan en cuanto al incentivo de la participación ciudadana y del control social de los medios, en la ley boliviana se atribuye un espacio importante a los pueblos indígenas originarios campesinos, históricamente excluidos y marginados del espectro mas mediático, y de otros aspectos de la vida social. Otro elemento novedoso y revolucionario, tanto en Venezuela como en Bolivia, ha sido el fortalecimiento de los medios alternativos y comunitarios, que responden a un nuevo concepto de medios de comunicación, donde se intenta retomar ese sentido originario de la 'comunicación' como 'poner en común, compartir algo'.

En Brasil, se ha desarrollado un extenso movimiento que se agrupa en el Foro Nacional por la Democratización de la Información (FNDC), que elaboró una Plataforma para un nuevo Marco de Comunicaciones, que contiene 20 puntos dentro de los que destacan el fortalecimiento de las radios y la televisión comunitaria, el fin del monopolio y el oligopolio de las empresas de comunicación, y la creación de un Consejo Nacional de Comunicación. Ese Movimiento se ha convertido en un 
poderoso actor social en la lucha por la regulación y democratización de las comunicaciones.

Otro medio es posible. Pero más allá de los argumentos que puedan expresar los medios, y de los resultados legislativos que se puedan obtener, es necesario insistir y militar en la apertura de espacios que democraticen los medios de comunicación y que involucren la participación ciudadana para que el mensaje no vaya indefectiblemente en una sola dirección y sin ningún tipo de regulación.

\section{Los medios en pro de valores saludables}

A pesar de ser conscientes de la naturaleza perversa de los medios masivos de comunicación en la sociedad capitalista, es importante destacar la posibilidad y necesidad de rescatar su función educativa, y su utilización para la promoción de valores saludables. Ello puede lograrse a través de alianzas estratégicas para el trabajo conjunto en determinadas campañas de promoción de la salud. Hay ejemplos positivos, como es el caso de la promoción del uso de preservativos en el marco de campańas para la prevención de las enfermedades de transmisión sexual, o la prevención de accidentes de tránsito, la promoción de las mamografías, la planificación familiar... en las cuales los medios de comunicación han participado, convirtiéndose en fuente muy importante de información. En muchas de estas campañas se ha trabajado conjuntamente con los Ministerios de Salud y agencias internacionales en salud, siguiendo los lineamientos de la Carta de Ottawa para la Promoción de la Salud aprobada en 1986. Existen experiencias exitosas como la creación del Canal Salud en Brasil (impulsado y sostenido por la Fundación Osvaldo Cruz), o los excelentes programas educativos de la televisión cubana, que actúan promoviendo valores y actitudes saludables. Esto indica que no es imposible trabajar en conjunto con los medios masivos de comunicación, que ciertamente siguen siendo la principal fuente de información de la población. Pero en cada campaña de salud que se diseñe es necesario tener presente la naturaleza de estos medios y los intereses que ellos representan, no para seguirles el juego a fin de ganarse su apoyo irrestricto, sino para ser más asertivos en las propuestas que se emprendan. Al mismo tiempo, la promoción de la salud, donde uno de los ejes centrales es la información y la educación, debe pensarse más allá de los tradicionales medios masivos de comunicación.

\section{Nuevos modelos de comunicar en salud}

Es necesario entender, como lo hemos señalado anteriormente, que la comunicación trasciende lo que conocemos como medios masivos de comunicación (prensa, radio y TV), y una buena campaña de prevención o de promoción de la salud puede ser mucho más efectiva si se tiene un contacto constante con la población a la que queremos llegar. Por ello, no sólo es necesario enfatizar en los programas de comunicación desde los centros de salud, sino también estructurar campañas comunicativas que prioricen el aspecto de participación de la sociedad y del contacto directo.

Es llamativa la proliferación de radios y televisoras comunitarias que, además de confrontar el pensamiento hegemónico, vienen promoviendo valores y principios diferentes a los que dominan en la sociedad capitalista. Estos medios pueden ser un instrumento importante para la promoción de la salud y para confrontar las conductas y hábitos nocivos y perjudiciales. Estas iniciativas nos obligan a repensar el modelo de comunicación. Ello implica incorporar a las personas y comunidades como sujetos activos en este proceso. Es indispensable entender la necesidad de un nuevo modelo de desarrollo y consumo, diferente al promovido por los medios de comunicación masivos controlados por el gran capital. Es necesario propiciar una reflexión que nos permita construir nuevos modelos de comunicación, más democráticos y participativos, que seguramente tendrán un mejor impacto en la vida y la salud de la población. 


\section{Referências}

ADORNO, T. Prólogo a la Televisión: en intervenciones; nuevos modelos de crítica. Caracas: Monte Ávila, 1969.

AGUDED, J. El fundamentalismo de la imagen en la sociedad del espectáculo. Anuario ININCO, Caracas, v. 1, n. 14, p. 11-29, 2002.

BRITTO GARCÍA, L. Dictadura Mediática en Venezuela: investigación de unos medios por encima de toda sospecha. Caracas: Edición del Ministerio del Poder Popular para la Comunicación y la Información, 2008.

CARMONA, E. Los amos de la prensa. Disponible en: < http:// www.iade.org.ar/modules/noticias/article.php.storyid=1740>. Acceso en 30 nov. 2011.

CERBINO, M. Sobre la libertad de expresión. Disponible en: <http://maurocerbino.blogspot.com>. Acceso en 02 dic. 2011.

CHOMSKY, N.; HERMAN, E. Los guardianes de la libertad. Barcelona: Grijalbo Mondadori, 1990.

DEBRAY, R. Vida y muerte de la imagen. Barcelona: Paidós, 1994.

DE MORAIS, D. La Cruzada de los medios en América Latina; Gobiernos progresistas y Políticas de Comunicación. Buenos Aires: Paidós, 2011.

FLORES, C. Lanza Obama campaña de prevención contra el AH1N1. Disponible en: < http://www.oem.com.mx/oem/notas/ n1308754.htm>. Acceso en 02 dic. 2011.

GALEANO, E. Nunca tantos habían sido incomunicados por tan pocos. Entrevista realizada por Niels Boel para Cultura de la Rebelión, el 02/10/2009. Disponible en: <http://www.rosablindada.info/?p=184>. Acceso en 30 nov. 2011.
LIPPMANN, W. La opinión pública. Madrid: Langre, 1992.

MAGNAGLOBAL. Advertising Forecast. Disponible en: <http://www. neoadvertising.com/ch/wp-content/uploads/2011/06/2011MAGNAGLOBAL-Advertising-Forecast Abbreviated.pdf>. Acceso en 14 jun. 2012.

ORGANIZACIÓN PANAMERICANA DE LA SALUD. La rentabilidad a costa de la gente: actividades de la industria tabacalera para comercializar cigarrillos en América Latina y el Caribe. Washington: OPS, 2002.

PHILIP MORRIS INC. PMI Reports 2011: Third-quarter results. London: Philip Morris Press Release, 2011. Disponible en: <http:// www.pmi.com>. Acceso en 02 dic. 2011.

RAMONET, I. Los culpables de la gripe porcina. Disponible en: $<$ http://www.rebelion.org/ noticia.php ?id=86425>. Acceso en 02 dic. 2011.

- Mafias farmacéuticas. Disponible en: <http://www. rebelion.org/noticia . php?id=90805>. Acceso en 01 dic. 2011.

SARTORI, G. Homo videns: la sociedad teledirigida. Madrid:Taurus, 1998.

SHAH, S. Cómo alteran las empresas privadas la agenda de salud pública mundial. Disponible en: <http://www.rebelion.org/ noticia.php?id=139439>. Acceso en: 02 dic. 2011.

SINGH, K. Sida, transnacionales y guerra de precios. Revista del Sur, Montevideo, n. 119/120, sep.-oct. 2011.

VILLEGAS, E. Abril, golpe adentro. Caracas: Editorial Galac, 2009.

Recebido para publicação em Setembro/2012

Versão final em Novembro/2012

Conflito de interesse: Não houve.

suporte financeiro: Inexistente. 